\title{
Inhibitory Effects of a Rice Hull Constituent on Tumor Necrosis Factor $\alpha$, Prostaglandin E2, and Cyclooxygenase-2 Production in Lipopolysaccharide-Activated Mouse Macrophages
}

\author{
SHENG-TUNG HUANG,${ }^{a}$ CHIEN-TSU CHEN,${ }^{a}$ KUR-TA CHIENG,${ }^{a}$ \\ SHIH-HAO HUANG, ${ }^{b}$ BEEN-HUANG CHIANG, ${ }^{b}$ LENG-FANG WANG, ${ }^{a}$ \\ HSIEN-SAW KUO ${ }^{a}{ }^{\text {AND CHUN-MAO LIN }}{ }^{a}$ \\ ${ }^{a}$ College of Medicine, Taipei Medical University, Taipei, Taiwan \\ ${ }^{b}$ Graduate Institute of Food Science and Technology, National Taiwan University, \\ Taipei, Taiwan
}

\begin{abstract}
Isovitexin, isolated from rice hull of Oryza sativa, has been characterized as a potent antioxidant. Its antioxidant activity, determined on the basis of inhibition of lipid peroxidation by the Fenton reaction, was comparable with that of $\alpha$-tocopherol, a well-established antioxidant. Isovitexin was able to reduce the amount of hydrogen peroxide production induced by lipopolysaccharide (LPS) in mouse macrophage RAW264.7 cells. In this study, we assessed its effects on the production of tumor necrosis factor $\alpha$ (TNF- $\alpha$ ), prostaglandin E2 $\left(\mathrm{PGE}_{2}\right)$, and the expression of cyclooxygenase-2 (COX-2) in LPS-activated RAW 264.7 macrophages. Isovitexin inhibited the release of TNF- $\alpha$, a proinflammatory cytokine, upon LPS activation with a $50 \%$ inhibitory concentration $\left(\mathrm{IC}_{50}\right)$ of 78.6 $\mu$ M. Isovitexin markedly reduced LPS-stimulated PGE $_{2}$ production in a concentration-dependent manner, with an $\mathrm{IC}_{50}$ of $80.0 \mu \mathrm{M}$. The expression of COX-2 was also inhibited by isovitexin treatment. Our results suggest that suppression of ROS-mediated COX-2 expression by isovitexin is beneficial in reducing inflammation and carcinogenesis.
\end{abstract}

KeYwORDs: antioxidant; inflammation; isovitexin; COX-2; $\mathrm{PGE}_{2}$; tumor necrosis factor

\section{INTRODUCTION}

Oxidative stress has been implicated in a variety of pathological processes, including aging, cancer, diabetes mellitus, atherosclerosis, neurological degeneration, and arthritis. Increased uptake of antioxidants may prevent organ injury associated

Address for correspondence: Chun-Mao Lin, Ph.D., College of Medicine, Taipei Medical University, No. 250, Wu-Hsing Street, Taipei 110, Taiwan. Voice: +886-2-27361661 ext. 3152; fax: +886-2-27361661 ext. 3163 .

cmlin@tmu.edu.tw

Ann. N.Y. Acad. Sci. 1042: 387-395 (2005). () 2005 New York Academy of Sciences.

doi: 10.1196/annals.1338.059 
with excessive generation of reactive oxygen species (ROS) ${ }^{1,2}$ ROS have been shown to initiate a wide range of toxic oxidative reactions. ${ }^{3}$ The effects of oxidants on signaling pathways are often characterized as resulting from heightened oxidative stress. Many antioxidants also exhibit anti-inflammatory effects. Theses observations provide a significant molecular basis for understanding the mode of actions of selected dietary ingredients in preventing diseases associated with heightened oxidative stress.

Tumor necrosis factor $\alpha$ (TNF- $\alpha)$, a proinflammatory cytokine, and prostaglandin $\mathrm{E} 2\left(\mathrm{PGE}_{2}\right)$ are key mediators in inflammatory reaction. TNF- $\alpha$ generated in inflammation may induce tissue damage. ${ }^{4}$ Prostaglandins, especially $\mathrm{PGE}_{2}$, are involved in stimulating cell proliferation, tumor growth, and suppressing the immune response to malignant cells. Overproduction of prostaglandins from upregulation of cyclooxygenase-2 (COX-2) in cells had been associated with malignant growth. ${ }^{5}$ COX-2 is rapidly induced by tumor promoters, growth factors, cytokines, and mitogens in various cell types. ${ }^{6}$ Many cell types associated with inflammation, such as macrophages and endothelial cells and fibroblasts, may be induced to overexpress COX-2. ${ }^{7}$ Treatment with TPA (12-O-tetradecanoyl-phobol-13-acetate) in mice led to edema and papilloma formation by enhancing COX-2 expression. Specific COX-2 inhibitors could counteract these biological events. Suppression of COX-2 induction and or its activity may be an effective approach for the prevention of carcinogenesis in several organs. Selected inhibitors of COX-2 may also have a therapeutic role in certain cancers.

Rice is an important dietary staple in Asia, where the incidence of breast and colon cancer is markedly lower than that in the western world. ${ }^{8}$ It has been reported that rice constituents counteract chemical-induced mutagenicity, tumor promotion, and carcinogenicity. ${ }^{9}$ Constituents from rice bran have been found to be beneficial for cancer prevention by epidemiological survey. Rice bran contains several classes of chemopreventive agents (e.g., flavonoids and their glycosides, tocotrienols, and $\gamma$-oryzanol). Isovitexin and related flavonoids are constituents of the rice hull of Oryza sativa and have been shown to exhibit potent antioxidant activity, ${ }^{10}$ including inhibition of xanthine oxidase, protection of DNA from oxidative damage, and prevention of heavy-metal-induced cell injury. ${ }^{11}$ Here, we further studied the antioxidative properties of isovitexin by examining its effects on LPS-induced $\mathrm{PGE}_{2}$ and TNF- $\alpha$ production and COX-2 expression in the murine macrophage-like cell line RAW264.7.

\section{MATERIALS AND METHODS}

\section{Materials}

Isovitexin, a glycosylflavonoid, was isolated from rice hull as described previously. ${ }^{12}$ The final product showed a major peak on capillary chromatography (P/ACE 5000; $75 \mu \mathrm{m} \times 37 \mathrm{~cm}$ [Beckman, Fullerton, CA]; borax buffer, $20 \mathrm{mM}, \mathrm{pH}=10.0$; $\mathrm{UV}$ absorbance at $214 \mathrm{~nm} ; 25^{\circ} \mathrm{C}$; UV absorbance at $214 \mathrm{~nm}, 25^{\circ} \mathrm{C}, 10 \mathrm{~K}$ voltage; injection pressure, $80 \mathrm{psi}$; migration time: $6.64 \mathrm{~min}$.). LPS (Escherichia coli O127:B8) and chemicals were purchased from Sigma (St. Louis, MO) unless specified. 


\section{Cell Culture}

The mouse monocyte-macrophage cell line RAW 264.7 (ATCC TIB-71) was cultured in Dulbecco's modified Eagle's medium (Gibco, Grand Island, NY) supplemented with $10 \%$ heat-inactivated fetal bovine serum (Gibco). Cells were plated in 24-well plates or petri dishes before activation by LPS (100 ng/mL). Isovitexin dissolved in dimethyl sulfoxide (DMSO) with the final DMSO concentration of less than $0.2 \%$ (vol/vol) was administered with LPS. Control samples contained the same concentration of DMSO.

\section{Lipid Peroxidation}

Ethyllinoleate was oxidized by the Fenton reaction $\left(\mathrm{Fe}^{2+} / \mathrm{H}_{2} \mathrm{O}_{2}\right)$. In selected experiments, equal concentration $(30 \mu \mathrm{M})$ of apigenin, isovitexin, and $\alpha$-tocopherol were added to $0.5 \mathrm{~mL}$ of an aqueous solution containing $1.5 \mathrm{mg} / \mathrm{L}$ ethyl linoleate, $0.25 \mathrm{mM}$ Trizma-HCl/0.75 mM KCl buffer ( $\mathrm{pH} 7.4$ ), $0.2 \% \mathrm{~N}$-lauroyl sarcosine, $1 \mu \mathrm{M}$ ferrous chloride, and $0.5 \mu \mathrm{M}$ hydrogen peroxide in a 2 -mL microtube. The mixture was incubated for $16 \mathrm{~h}$ at $37^{\circ} \mathrm{C}$. The quantity of oxidation was measured by the thiobarbituric acid (TBA) assay. ${ }^{11}$ The antioxidative activity of the samples was calculated according to the following formula: antioxidative activity $(\%)=1-(\mathrm{ab}-$ sorbance of sample/absorbance of control) $\times 100$. The level of TBA-reactive substance (TBARS) by autooxidation of ethyllinoleate was calculated as the amount of malondialdehyde.

\section{Determination of TNF- $\alpha$ Release}

Murine macrophages were seeded in 24 -well plates at a density of $5.0 \times 10^{5}$ cells/ well the day before the experiment. Cells were treated with or without isovitexin $(10-100 \mu \mathrm{M})$ and/or LPS $(100 \mathrm{ng} / \mathrm{mL})$ in $500 \mu \mathrm{L}$ of medium containing $10 \%$ fetal bovine serum for $1 \mathrm{~h}$ at $37^{\circ} \mathrm{C}$. TNF- $\alpha$ levels in the media were then determined by a quantitative sandwich enzyme-linked immunosorbent assay using the commercially available mouse TNF- $\alpha$ immunoassay kit (Amersham, Buckinghamshire, UK) according to the manufacturer's instructions. All experiments were done in triplicate. ${ }^{13}$

\section{$P G E_{2}$ Assay}

Cells were plated at a density of $1.0 \times 10^{6}$ cells $/ \mathrm{mL}$ in 24 -well culture plate and stimulated with LPS $(50 \mathrm{ng} / \mathrm{mL})$ in the presence or absence of various concentrations of isovitexin for $18 \mathrm{~h}$. The culture medium of control and treated cells was collected and centrifuged. The level of $\mathrm{PGE}_{2}$ released into culture medium was determined using an enzyme immunoassay according to the manufacturer's instructions (Amersham, Buckinghamshire, UK). ${ }^{4}$

\section{Western Blotting}

The cellular protein fraction was prepared using lysis buffer containing $10 \%$ glycerol, $1 \%$ Triton X-100, $1 \mathrm{mM}$ sodium orthovanadate, $1 \mathrm{mM}$ EGTA, $5 \mathrm{mM}$ EDTA, $10 \mathrm{mM}$ NaF, $1 \mathrm{mM}$ sodium pyrophosphate, $20 \mathrm{mM}$ Tris- $\mathrm{HCl}(\mathrm{pH} 7.9), 100 \mu \mathrm{M} \beta$ glycerophosphate, $137 \mathrm{mM} \mathrm{NaCl}, 1 \mathrm{mM}$ phenylmethylsulfonyl fluoride (PMSF), $10 \mu \mathrm{g} / \mathrm{mL}$ aprotinin, and $10 \mu \mathrm{g} / \mathrm{mL}$ leupeptin. Proteins $(50 \mu \mathrm{g})$ were separated on so- 
dium dodecyl sulfate-polyacrylamide gel electrophoresis (SDS-PAGE) and electrotransferred to a polyvinylidene difluoride (PVDF) membrane (Immobilon-P; Millipore, Bedford, MA). The membrane was incubated with an anti-COX-2 monoclonal antibody (Oncogene Science, Cambridge, UK) containing 1\% bovine serum albumin and $0.2 \% \mathrm{NaN}_{3}$ overnight at $4{ }^{\circ} \mathrm{C}$. After incubation with horseradish peroxidase-conjugated anti-mouse immunoglobulin G antibody (Oncogene Science, Cambridge, UK), the immunoreactive bands were visualized with enhanced chemiluminescent reagents (ECL; Amersham, Buckinghamshire, UK). Relative protein content in each band was assessed using a densitometer (Alpha Innotech IS-1000; Digital Imaging System, San Leandro, CA).
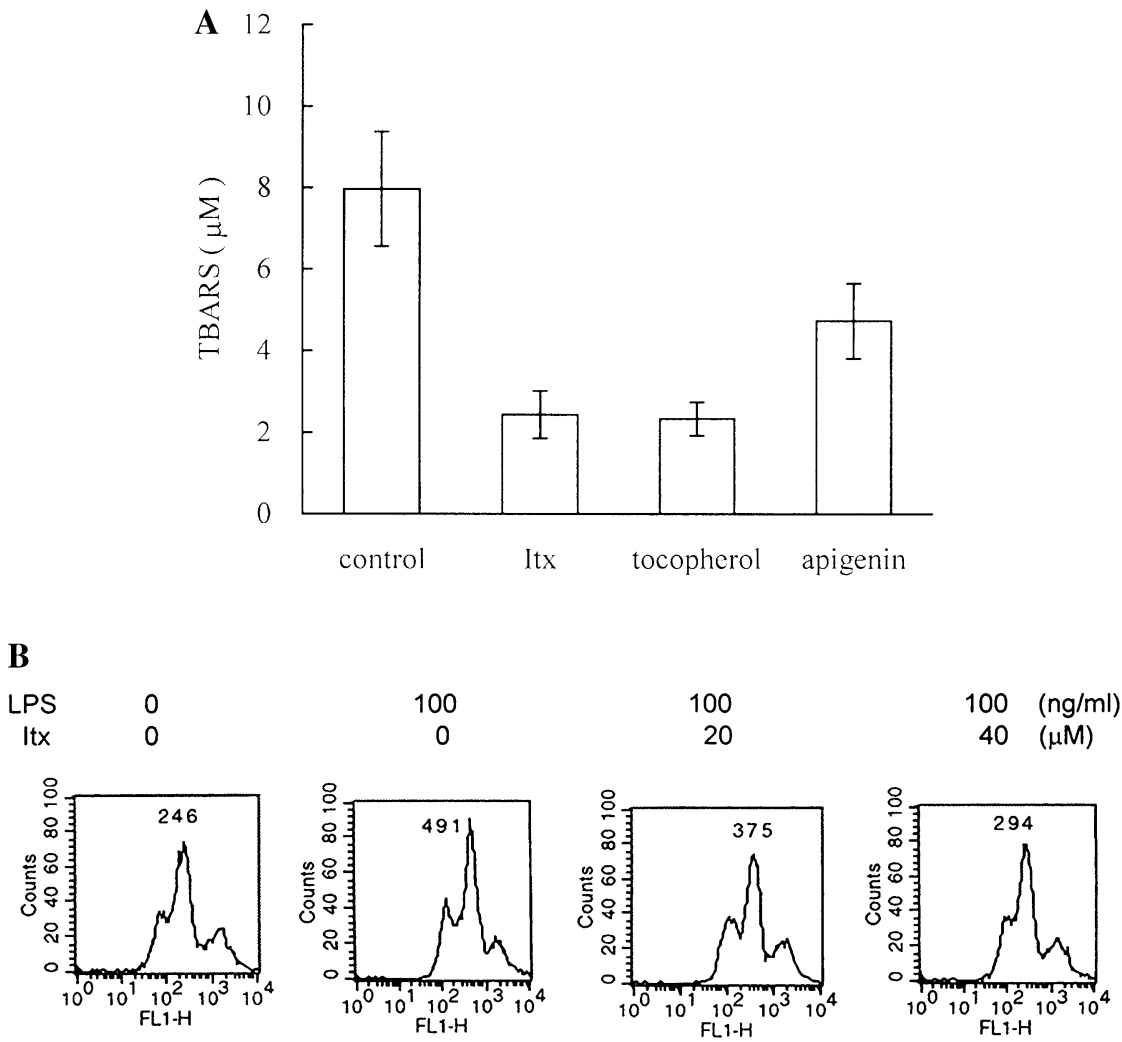

FIGURE 1. Antioxidative activity of isovitexin. (A) Isovitexin (Itx) inhibited the Fenton reaction-induced lipid peroxidation. Isovitexin (Itx), $\alpha$-tocopherol, and apigenin (30 $\mu \mathrm{M}$ ) were compared on the basis of their antioxidative activities. Quantity of oxidation was measured using the TBA assay. Antioxidative activity of the samples was measured according to levels of TBA-reactive substance (TBARS). (B) Isovitexin suppressed LPS-induced production of hydrogen peroxide. RAW 264.7 cells were treated with LPS (100 ng/mL) alone or LPS and isovitexin $(20$ and $40 \mu \mathrm{M})$ for $30 \mathrm{~min}$. Cells were stained with DCFH-DA and subjected to flow cytometry. Peaks of FL1-H fluorescence intensity are indicated for each treatment. 


\section{Flow Cytometric Detection of Hydrogen Peroxide}

RAW 264.7 cells were suspended in phenol red-free medium at a density of $10^{5}$ cells $/ \mathrm{mL}$. Cells were stained with $100 \mu \mathrm{M} 2^{\prime}, 7^{\prime}$-dichlorofluorescin diacetate (DCFH-DA) in the dark for 30 min and then analyzed using a FACScan (Becton Dickinson, San Jose, CA). Oxidation of green DCH fluorescence by hydrogen peroxide in living cells was detected using the FL1-H wavelength band. The fluorescence signals of 10,000 cells were processed using a logarithmic amplifier as described previously. ${ }^{14}$

\section{RESULTS AND DISCUSSION}

\section{Antioxidative Activity of Isovitexin}

Many antioxidants exert anti-inflammatory effects, and many polyphenolic compounds have been reported to be potent ROS scavengers. The antioxidative activity of isovitexin was evaluated by the TBA method. The inhibitory effect on ethyllinoleate oxidation by isovitexin $(69.5 \%$ inhibition, TBARS value $=2.43 \mu \mathrm{M})$ was comparable to that of $\alpha$-tocopherol $(70.8 \%$ inhibition, TBARS value $=2.33 \mu \mathrm{M})$ and higher than that of apigenin, an aglycon flavonoid, (40.7\% inhibition, TBARS value $=4.73 \mu \mathrm{M})($ FIG. 1A). The results suggest that isovitexin is a potent antioxidant. Isovitexin also lowered the LPS-induced increase in the cellular content of hydrogen peroxide in RAW 264.7 macrophage cells in a dose-dependent manner (FIG. 1B).

\section{Isovitexin Inhibition of TNF- $\alpha$ Production}

To determine the effect of isovitexin on LPS-activated TNF- $\alpha$ production, we stimulated the cells with LPS in the presence or absence of isovitexin at concentra-

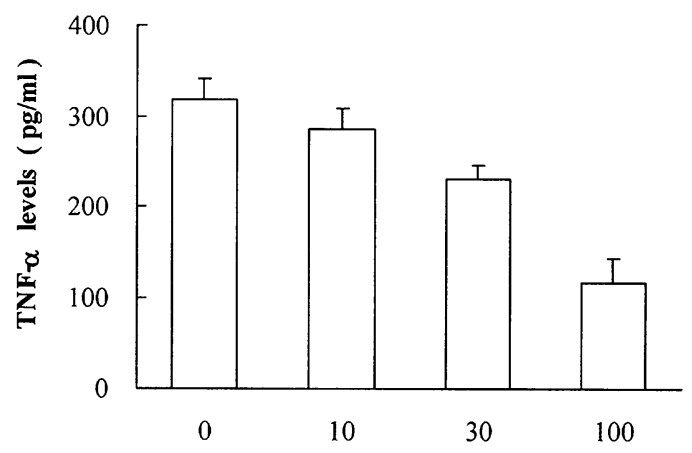

FIGURE 2. Inhibition of TNF- $\alpha$ production by isovitexin. RAW 264.7 cells were treated with LPS $(100 \mathrm{ng} / \mathrm{mL})$ in the presence or absence of isovitexin (Itx) $(0,10,30$, and 100 $\mu \mathrm{M}$, respectively) for $1 \mathrm{~h}$. Amount of TNF- $\alpha$ released into culture medium was determined. Data are presented as means \pm standard error of the mean $(n=3)$. 
tions ranging from 10 to $100 \mu \mathrm{M}$ for 60 min. The production of TNF- $\alpha$ by the unstimulated RAW 264.7 cells was $20 \mathrm{pg} / \mathrm{mL}(n=3)$. Incubation of these cells with LPS $(100 \mathrm{ng} / \mathrm{mL})$ for $1 \mathrm{~h}$ caused a substantial increase in TNF- $\alpha$ production $(318.9 \mathrm{pg} / \mathrm{mL} ; n=3)$. When RAW 264.7 cells were stimulated with LPS in the presence of isovitexin (10-100 $\mu \mathrm{M})$, a concentration-dependent inhibition of TNF- $\alpha$ production with a $50 \%$ inhibitory concentration $\left(\mathrm{IC}_{50}\right)$ value of $78.6 \mu \mathrm{M}$ was observed (FIG. 2).

\section{Isovitexin Inhibition of $\mathrm{PGE}_{2}$ Production and COX-2 Expression}

The effect of isovitexin on $\mathrm{PGE}_{2}$ production and COX-2 protein expression following LPS stimulation was examined $18 \mathrm{~h}$ after treatment with LPS $(50 \mathrm{ng} / \mathrm{mL})$. $\mathrm{PGE}_{2}$ production was reduced in a concentration-dependent manner with an $\mathrm{IC}_{50}$ of $80.0 \mu \mathrm{M}$ (FIG. 3A). The inhibition was not due to general cellular toxicity (data not shown). LPS-induced COX-2 protein expression was also suppressed by isovitexin in a concentration-dependent manner after treatment for $18 \mathrm{~h}$. The relative protein levels of COX-2 in the presence of $20,40,60,80$, and $100 \mu \mathrm{M}$ isovitexin were 1.02,

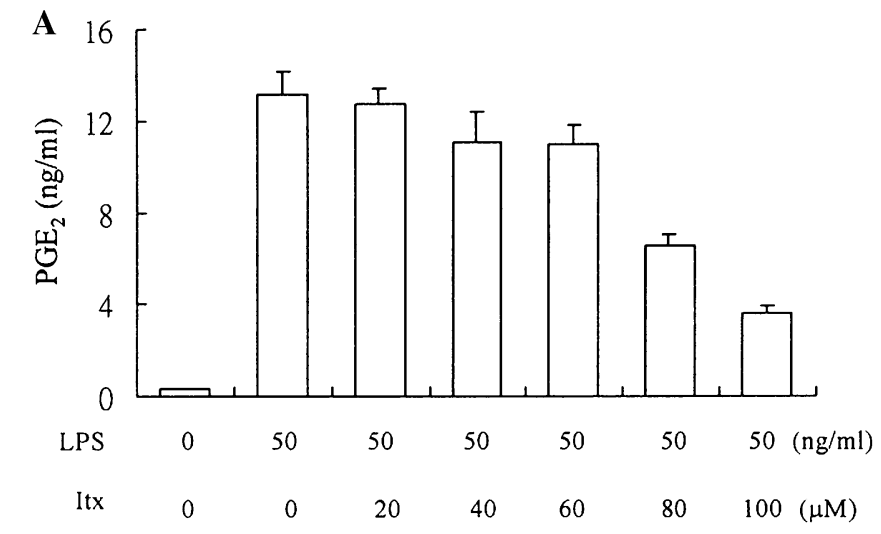

$\begin{array}{rrrrrrrr}\text { B LPS } & 0 & 50 & 50 & 50 & 50 & 50 & 50(\mathrm{ng} / \mathrm{ml}) \\ \text { Itx } & 0 & 0 & 20 & 40 & 60 & 80 & 100(\mu \mathrm{M})\end{array}$

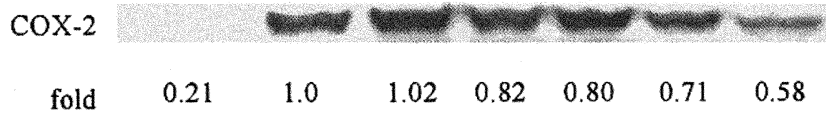

FIGURE 3. Effects of isovitexin on LPS-induced $\mathrm{PGE}_{2}$ generation and COX-2 expression. (A) Cells were treated with LPS $(50 \mathrm{ng} / \mathrm{mL})$ in the presence or absence of isovitexin (Itx) for $18 \mathrm{~h}$. Amount of $\mathrm{PGE}_{2}$ released into culture medium was determined. Data are presented as means \pm standard error of the mean $(n=3)$. (B) Values for expression of COX-2 protein upon various treatments for $18 \mathrm{~h}$ were quantities after resolving in 8.0\% SDS- PAGE and Western blot analysis. Relative level of COX-2 expression observed with LPS alone was set at 1.0. 
$0.82,0.80,0.71$, and 0.58 , respectively, in reference to a value of 1.00 in samples treated with LPS alone (FIG. 3B).

\section{APossible Mechanism for Isovitexin Inhibition of LPS Activity}

Macrophages release various mediators in cellular inflammatory response. Among those released are ROS including $\mathrm{H}_{2} \mathrm{O}_{2}$, nitric oxide, superoxide, and hydroxyl radical. The intracellular ROS production is associated with several cellular events including the activation of NAD(P)H oxidase, xanthine oxidase, and the cellular mitochondrial respiratory chain. ${ }^{15,16}$ ROS thus formed are potent activators of $\mathrm{NF}-\kappa \mathrm{B}$, an essential transcription factor in the inflammatory signal transduction pathway. ${ }^{17}$ ROS plays an essential role in the initiation of the NIK/MAPK cascade to trigger a series of responses in which $\mathrm{I} \kappa \mathrm{B}$ is phosphorylated to free NF- $\kappa \mathrm{B}$ from I $\kappa \mathrm{B}$ inhibition. ${ }^{18}$ The active form of NF- $\kappa \mathrm{B}$ is translocated from cytoplasm to the nucleus to bind the cognate NF- $\kappa \mathrm{B}$ binding site in the promoter regions of genes including COX-2. ${ }^{19,20} \mathrm{COX}-2$ overexpression mediated by activation of NF- $\kappa \mathrm{B}$ is a possible molecular mechanism in cellular transformation to neoplasia. Another consequence of excessive ROS generation is oxidative DNA damage leading to gene

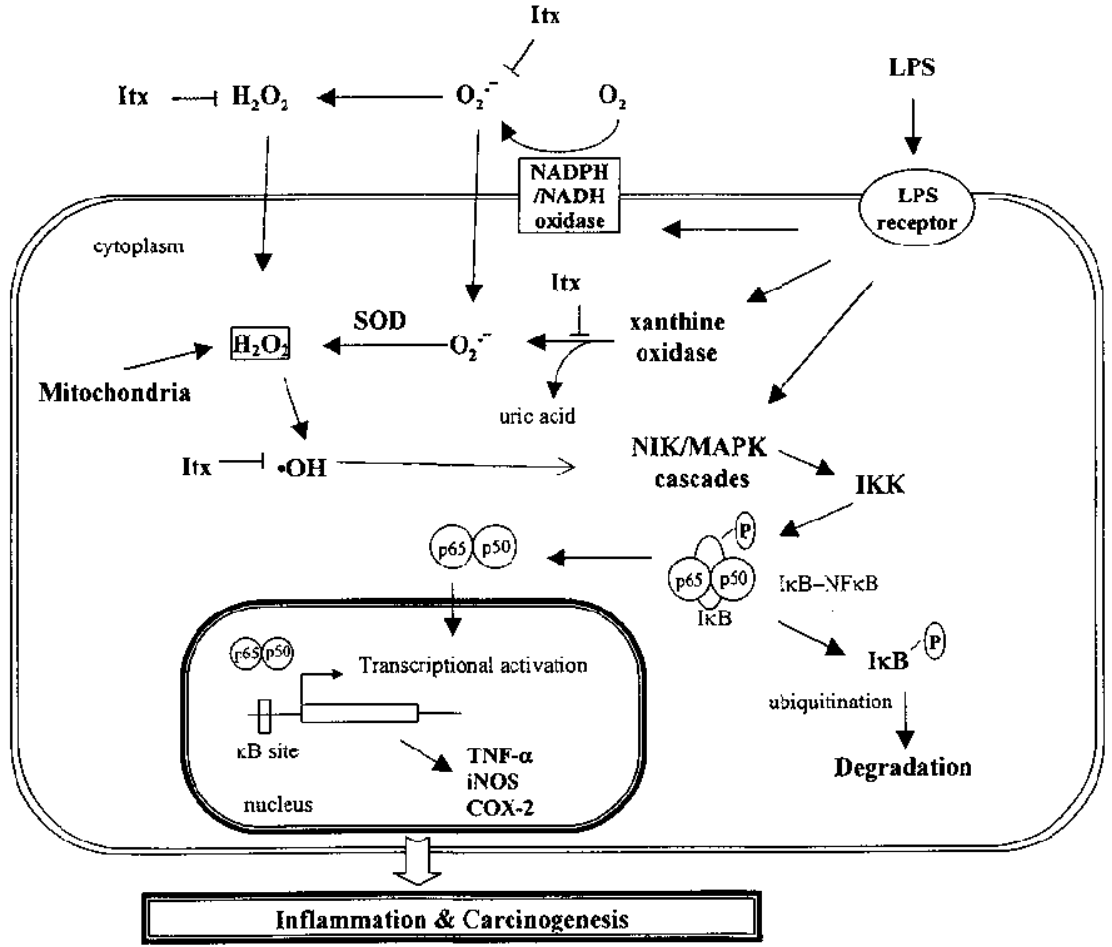

FIGURE 4. Possible mechanisms in which isovitexin (Itx) exerts its action against inflammation and carcinogenesis. 
mutations and cancer formation. The inflammation-signaling transduction pathway mediated by LPS on macrophage is depicted in FIGURE 4.

In FIGURE 4, the roles of isovitexin in inhibiting inflammation and carcinogenesis are proposed. Isovitexin, with its potent antioxidant activity, is likely to suppress NF$\kappa \mathrm{B}$ activation. This contention is supported by the finding that the expression of TNF- $\alpha$ and COX-2, both transactivated by NF- $\kappa B$, was suppressed by isovitexin. Reduced $\mathrm{PGE}_{2}$ formation by isovitexin is likely due to its inhibition of COX-2 expression.

In summary, isovitexin is a potent antioxidant that inhibits TNF- $\alpha$ and COX- 2 expression caused by LPS in mouse macrophage RAW264.7 cells. This effect of isovitexin is likely due to its inhibition of NF- $\mathrm{KB}$ activation via its antioxidant activity. Isovitexin also inhibits $\mathrm{PGE}_{2}$ formation, likely secondary to its suppression of COX2 expression. These antioxidant and anti-inflammatory effects of isovitexin may have implications in carcinogenesis. Isovitexin is a food phytochemical enriched in rice. Whether lower incidence of selected neoplasia such as breast and colon cancer in countries with rice as a major staple can be attributed to the antioxidant gradients in rice including isovitexin remains to be determined.

\section{ACKNOWLEDGMENTS}

This study was supported by grants from the National Science Council (NSC922113-M-038-005 and NSC92-2113-M-038-003).

\section{REFERENCES}

1. FitZPAtRick, F.A. 2001. Inflammation, carcinogenesis and cancer. Int. Immunopharmacol. 1: 1651-1667.

2. Pavlick, K.P., F.S. Laroux, J. Fuseler, et al. 2002. Role of reactive metabolites of oxygen and nitrogen in inflammatory bowel disease. Free Radic. Biol. Med. 33: 311-322.

3. Cuzzocrea, S., D.P. Riley, A.P. Caputi, et al. 2001. Antioxidant therapy: a new pharmacological approach in shock, inflammation, and ischemia/reperfusion injury. Pharmacol. Rev. 53: 135-159.

4. JU, H.K., S.H. BAEK, R.B. AN, et al. 2003. Inhibitory effects of nardostachin on nitric oxide, prostaglandin E2, and tumor necrosis factor-alpha production in lipopolysaccharide activated macrophages. Biol. Pharm. Bull. 26: 1375-1378.

5. Crofford, L.J., R.L. Wilder, A.P. RistimaKi, et al. 1994. Cyclooxygenase-1 and -2 expression in rheumatoid synovial tissue. Effects of interleukin-1 $\beta$, phorbol ester, and corticosteroids. J. Clin. Invest. 93: 1095-1101.

6. Inoue, H., C. Yokoyama, S. Hara, et al. 1995. Transcriptional regulation of human prostaglandin-endoperoxide synthase-2 gene by lipopolysaccharide and phorbol ester in vascular endothelial cells. J. Biol. Chem. 270: 24965-24971.

7. Hla, T., A. Ristimaki, S. Appleby, et al. 1993. Cyclooxygenase gene expression in inflammation and angiogenesis. Ann. N.Y. Acad. Sci. 696: 197-204.

8. Koo, L.S., O.W. MANG, \& J.H. Ho. 1997. An ecological study of trends in cancer incidence and dietary changes in Hong Kong. Nutr. Cancer 28: 289-301.

9. Takeshita, M., S. Nakamura, F. Makita, et al. 1992. Antitumor effect of RBS (rice bran saccharide) on ENNG-induced carcinogenesis. Biotherapy 4: 139-145.

10. Ramarathnam, N., T. Osawa, M. Namiki, et al. 1989. Chemical studies on novel rice hull antioxidants. 2. Identification of isovitexin, a C-glycosyl flavonoid. J. Agric. Food Chem. 37: 316-319. 
11. Lin, C.M., C.T. Chen, H.H. LeE, et al. 2002. Prevention of cellular ROS damage by isovitexin and related flavonoids. Planta Medica 68: 363-365.

12. Osawa, T., H. KatsuZaki, Y. Hagiwara, et al. 1992. A novel antioxidant isolated from young green barley leaves. J. Agric. Food Chem. 40: 1135-1138.

13. GAO, B. \& M.F. TSAN. 2003. Endotoxin contamination in recombinant human heat shock protein 70 (Hsp70) preparation is responsible for the induction of tumor necrosis factor alpha release by murine macrophages. J. Biol. Chem. 278: 174-179.

14. Ubezio P. \& F. Civoli. 1994. Flow cytometric detection of hydrogen peroxide production induced by doxorubicin in cancer cells. Free Radic. Biol. Med. 16: 509-516.

15. Irani, K., Y. Xia, J.L. ZweIER, et al. 1997. Mitogenic signaling mediated by oxidants in RAS-transformed fibroblasts. Science 275: 1649-1652.

16. LEE, S.F., Y.T. HUANG, W.S. WU, et al. 1996. Induction of c-jun protooncogene expression by hydrogen peroxide through hydroxyl radical generation and $\mathrm{p} 60^{\text {src }}$ tyrosine kinase activation. Free Radic. Biol. Med. 21: 437-448.

17. Schreck, R., P. Rieber, \& P.A. BAeuerle. 1991. Reactive oxygen intermediates as apparently widely used messengers in the activation of the NF-kappa B transcription factor and HIV-1. EMBO J. 10: 2247-2258.

18. Chen, C.C., \& J.K. WANG. 1999. p38 but not p44/42 mitogen-activated protein kinase is required for nitric oxide synthase induction mediated by lipopolysaccharide in RAW 264.7 macrophages. Mol. Pharmacol. 55: 481-488.

19. Schmidt, K.N., P. Amstad, P. Cerutti, et al. 1995. The roles of hydrogen peroxide and superoxide as messengers in the activation of transcription factor NF-kappa B. Chem. Biol. 2: 13-22.

20. Chun, K.S., H.H. ChA, J.W. Shin, et al. 2004. Nitric oxide induces expression of cyclooxygenase- 2 in mouse skin through activation of NF-kappaB. Carcinogenesis 25: $445-454$. 